\title{
Leptin Rapidly Induces the Expression of Metabolic and Myokine Genes in C2C12 Muscle Cells to Regulate Nutrient Partition and Oxidation
}

\author{
Yuriy Nozhenko Ana M. Rodríguez Andreu Palou \\ Laboratory of Molecular Biology, Nutrition and Biotechnology (Nutrigenomics), University of the \\ Balearic Islands (UIB) and CIBER Fisiopatología de la Obesidad y Nutrición (CIBEROBN), Palma de \\ Mallorca, Spain
}

\section{Key Words}

Peroxisome proliferator-activated receptor- $\gamma$ coactivator-1 $1 \alpha(P G C-1 \alpha) \cdot$ Uncoupling proteins (UCPs) • Muscle carnitine palmitoyl transferase 1 (mCPT1) • Pyruvate dehydrogenase kinase 4 (PDK4) • Interleukins

\begin{abstract}
Background: Skeletal muscle can experience pronounced metabolic adaptations in response to extrinsic stimuli, and expresses leptin receptor (OB-Rb). We aimed to further the understanding of leptin effects on muscle cells, by studying the expression of key energy metabolism genes in C2C12 myotubes. Methods: We performed a dose-time-dependent study with physiological concentrations of leptin: 5, 10 and 50ng/ml, for 0,30',3h, 6h, $12 \mathrm{~h}$ and $24 \mathrm{~h}$, also monitoring time-course changes in non-treated cells. mRNA levels were analyzed by RT-qPCR and peroxisome proliferator activated receptor $\gamma$ coactivator $1 \alpha$ (PGC1 $\alpha$ ) protein levels by western blot. Results: The most significant effects were observed with $50 \mathrm{ng} / \mathrm{ml}$ leptin. In the short-term (30' and/or 3h), leptin significantly induced the expression of PGC1 $\alpha$, muscle carnitine palmitoyl transferase 1 (mCPT1), uncoupling protein 3 (UCP3), OB-Rb, Insulin receptor (InsR) and interleukins 6 and 15 (IL6, IL15). There was a decrease in mRNA levels of pyruvate dehydrogenase kinase 4 (PDK4) and mCPT1 in the long-term (24h). PGC1 $\alpha$ protein levels were increased (24h). Conclusion: Leptin rapidly induces the expression of genes important for its own response and the control of metabolic fuels, with the rapid responses of the genes encoding the master regulator PGC1 $\alpha, \mathrm{mCPT} 1, \mathrm{UCP} 3, \mathrm{PDK} 4$ and the signaling secretory molecule IL6 particularly interesting.
\end{abstract}


Nozhenko/Rodríguez/Palou: Leptin and Metabolic Pattern in Muscle Cells

\section{Introduction}

Skeletal muscle has a high impact on energy metabolism in mammals, and exercise has been associated with improvements in sensitivity to the main metabolic hormones such as insulin and leptin [1,2]. Leptin is a hormone/adipokine, mainly produced by adipose tissue in proportion to fat mass, which regulates energy metabolism; it can decrease food intake and increase energy expenditure, both by communicating energy status to the brain (and thereby activating key signaling pathways) and by direct peripheral mechanisms, although it is also able to regulate several other processes such as immunity, glucose and lipid metabolism, reproduction, etc. [3]. The long isoform of the leptin receptor (OB-Rb) has been proposed as the only one with full-signaling capacity and is expressed in a wide range of tissues, with notable expression in hypothalamus and skeletal muscle [3, 4]. Leptin can activate several intracellular signaling pathways [4], and one of the main pathways involves JAK/STAT kinases/transcription factors [3]; by this same pathway leptin is able to control its own signaling by a negative feedback system mainly inducing the suppressor of cytokine signaling 3 (SOCS3), as studied in different cell types [3]. Another pathway involves the direct activation of AMP-activated protein kinase (AMPK) by leptin on muscle, promoting oxidative metabolism [5]. Moreover, Moon et al. have also shown the ability of leptin to activate, in muscle cells, the signaling pathways involving signal transducer and activator of transcription 3 (STAT3), Akt (protein kinase B -PKB) and extracellular signal-regulated kinase 1/2 (ERK1/2) [6], thus leptin seems to have a profound effect in muscular cells.

We have conducted previous studies with sequential models of gene expression analyses in vitro (analyzing the effects on muscle cells of free fatty acids either alone or in combination with exercise mimetics) and in vivo in soleus and gastrocnemius muscles (with fasting and refeeding) $[7,8]$ where we have highlighted the rapid modulation of gene expression levels of key metabolic/signaling genes such as peroxisome proliferator activated receptor (PPAR) gamma co-activator $1 \alpha$ (PGC1 $\alpha$ ), uncoupling protein (UCP) 3 , pyruvate dehydrogenase kinase 4 (PDK4) and interleukin (IL) 6. Interestingly, one important signal whose levels change in a time sequential mode with fasting and refeeding is circulating leptin [9], which is a primary signal (its decrease) in starvation [10].

Under this prospect, we aimed to shed light on the direct time- and dose-dependent effects of physiological concentrations of leptin in muscle cells in the expression of the above mentioned genes, and other key genes in energy metabolism and glucose/lipid fuel partition, as well as in the two main ILs ( 6 and 15 ) produced by muscle (recognized as myokines [11, 12]).

Along these lines, the nuclear receptors PPARs $(\alpha, \beta / \delta$ and $\gamma)$ are able to regulate energy metabolism, and have a crucial role controlling the partition of nutrients (such as glucose and lipids) as metabolic fuels $[13,14]$. Both PPAR $\alpha$ and $\beta / \delta$ are key in controlling fatty acid oxidation, and although PPAR $\beta / \delta$ shows greater expression in muscle, both are important in the control of muscle cell energy metabolism $[13,14]$. On the other hand, PPAR $\gamma$ is abundantly expressed in adipose tissue where is mainly involved in energy storage, although it is also involved in the stimulation of fatty acid oxidation in skeletal muscle [15].

With respect to PGCs, PGC1 $\alpha$ is the best known and binds PPAR $\gamma$ and other transcription factors, while PGC1 $\beta$ is also a co-activator of the PGC family but less known [16]. Both PGCs are involved in the promotion and control of mitochondrial biogenesis and respiratory metabolism [17]. In skeletal muscle, PGC1 $\alpha$ is known to have key functions in fatty acid oxidation, lipogenesis, myokine secretion, glucose uptake, fiber switching, etc. [16].

Regarding the uncoupling proteins UCP2 and UCP3, their expression seems to be controlled, among others, by PPARs [18]. UCP2 and 3 seem to be mainly involved in the protection of mitochondria by the mitigation of ROS production and/or, especially in the case of UCP3, in the export of fatty acid anions during lipid oversupply, protecting mitochondria from lipotoxicity $[19,20]$. Concerning PDK4, it is crucial in fuel selection since it inactivates the pyruvate dehydrogenase-PDH- complex [14]. 
Nozhenko/Rodríguez/Palou: Leptin and Metabolic Pattern in Muscle Cells

We have also studied the expression of: the Insulin receptor (InsR) (taking into account the crosstalk between leptin and insulin signaling [3]), the insulin regulated glucose transporter GLUT4 [21], and the muscle isoform of carnitine palmitoyl transferase 1 (mCPT1 or CPT1B) (rate-limiting enzyme involved the transport of fatty acids to the mitochondria for their oxidation [22]). Moreover, the expression of both PDK4 and mCPT1 is known to be regulated by PPAR $\alpha[14]$.

Last, but not least, IL6 and IL15 are signal molecules produced and/or secreted by muscle $[11,23]$. Muscle IL6 has been related to physical activity, muscle-adipose tissue crosstalk, the promotion of glucose-sensitizing and anti-inflammatory effects, etc; in fact it shares some roles with leptin in muscle like the capacity to activate AMPK [12].

We performed a time-sequential and dose-dependent model (similar to previous works $[7,8])$ of differentiated cultured muscle cells (C2C12) treated with leptin to characterize its effects on the expression of the strategic molecules described above. We describe here that leptin causes a rapid response of myocytes by inducing the expression of key genes involved in metabolic and fuel control (especially those codifying PGC1 $\alpha$, mCPT1, UCP3 and PDK4) and of the myokine IL6.

\section{Materials and Methods}

\section{Cell culture and leptin treatments}

Mouse C2C12 myoblasts (ATCC, Promochem, Barcelona, Spain) were used. Cells were grown in DMEM (containing $4500 \mathrm{mg} / \mathrm{L}$ (high) glucose) (Sigma Aldrich, Madrid, Spain) supplemented with 10\% Foetal Bovine Serum (Gibco-Invitrogen, Barcelona, Spain), antibiotics ( $50 \mathrm{IU} / \mathrm{ml}$ penicillin, $50 \mu \mathrm{g} / \mathrm{ml}$ streptomycin), $4 \mathrm{mM} \mathrm{L}$-glutamine and sodium pyruvate $1 \mathrm{mM}$ (Sigma Aldrich) (growth medium) in $5 \% \mathrm{CO}_{2}$ at $37^{\circ} \mathrm{C}$ in a humidified chamber. When the cells were $70-80 \%$ confluent, they were induced to differentiate into myotubes by placing them in a low-serum differentiation medium (DMEM with antibiotics, glutamine and $2 \%$ horse serum) for ten days. The differentiated myotubes were used for experiments. C2C12 myotubes were treated with DMEM (control) or leptin $(5,10$, and $50 \mathrm{ng} / \mathrm{ml}$ in DMEM) for $0.5,3,6,12$ and $24 \mathrm{~h}$. The recombinant murine leptin came from PeproTech (PeproTech, London, England). In our experimental design, we monitored the time-course changes in gene expression in both leptin-treated and non-treated cells (to have suitable time-controls) and the results given in the figures showing gene expression are given as a percentage increase of each treated time point with respect to their respective time controls; by doing this, we make sure that the observed differences are due to the treatment performed and not to timedependent oscillations in gene expression in the cultured cells.

\section{RNA isolation}

After adequate treatments, total RNA was extracted from C2C12 cells by Tripure Reagent (Roche Diagnostics GmbH, Mannheim, Germany) according to the manufacturer's instructions. Isolated RNA was quantified using the NanoDrop ND-1000 spectrophotometer (NadroDrop Technologies, Inc., Wilmington, $\mathrm{DE}, \mathrm{USA}$ ) and its integrity confirmed using agarose gel electrophoresis, and stored at $-80^{\circ} \mathrm{C}$.

\section{Protein isolation and quantification}

Protein samples from C2C12 cells were extracted from phenolic Tripure phase by adding $300 \mu \mathrm{l}$ of ethanol $100 \%$ at $4^{\circ} \mathrm{C}$ and agitating (by inverting) for $1 \mathrm{~min}$. Then, they were centrifuged at $2000 \mathrm{~g}$ for 5 $\min$ at $4^{\circ} \mathrm{C}$. Supernatant was collected and $1.5 \mathrm{ml}$ of isopropanol was added to each sample and mixed by inversion; after an incubation of 10', the samples were centrifuged at $12000 \mathrm{~g}$ for $10^{\prime}$ at $4^{\circ} \mathrm{C}$, keeping the pellet. After three washing steps with $2 \mathrm{ml}$ of Guanidine- $\mathrm{HCl} 0.3 \mathrm{M}$ in ethanol $95 \%$ and centrifugation at $7500 \mathrm{~g}$ for $5 \mathrm{~min}$ at $4^{\circ} \mathrm{C}, 2 \mathrm{ml}$ of Ethanol $100 \%$ was added to the pellet, with a following incubation for $20^{\prime}$ at room temperature and centrifugation at $7500 \mathrm{~g}$ for $5^{\prime}$ at $4^{\circ} \mathrm{C}$. The final pellet was dried by evaporation and was dissolved in $150 \mu \mathrm{l}$ SDS $2 \%$ and stored at $-20^{\circ} \mathrm{C}$ until Western blot analysis. Total protein amount was quantified by the BCA ${ }^{\text {TM }}$ Protein Assay Kit (Pierce, Rockford, IL, USA). 
Nozhenko/Rodríguez/Palou: Leptin and Metabolic Pattern in Muscle Cells

Table 1. Nucleotide sequences and amplicon size of primers used for PCR amplification. Abbreviations: Peroxisome proliferator activated receptor (PPAR) gamma coactivator 1 alpha (PGC1 $\alpha$ ) and beta (PGC1 $\beta$ ), PPAR $\alpha, \beta / \delta$ and $\gamma$, Glucose transporter GLUT4, Pyruvate dehydrogenase kinase 4 (PDK4), Muscle carnitine palmitoyl transferase 1b (mCPT1), Uncoupling protein 2 (UCP2) and 3(UCP3), Insulin receptor (InsR), long form of the Leptin receptor (OB-Rb), Suppressor of cytokine signaling 3 (SOCS-3), and Interleukins 6 (IL6) and 15 (IL15); base pairs (bp)

\begin{tabular}{lllc}
\hline Gene & \multicolumn{1}{c}{$\begin{array}{c}\text { Gene Forward primer } \\
\left(5^{\prime} \text { to } 3^{\prime}\right)\end{array}$} & \multicolumn{1}{c}{$\begin{array}{c}\text { Reverse primer } \\
\text { (5' to 3') }\end{array}$} & $\begin{array}{c}\text { Amplicon size } \\
\text { (bp) }\end{array}$ \\
\hline 18S & TAGAGGGACAAGTGGCGTTC & CGCTGAGCCAGTCAGTGT & 103 \\
PGC1 $\alpha$ & CCACCGCCAACCAAGAGGGC & AGCCGGAGACTGGGCCGTT & 167 \\
PGC1 $\beta$ & ACTGGATGAAGGCGACACAC & GCTTGCTGTTGGGGAGGA & 163 \\
PPAR $\alpha$ & AGTGCCCTGAACATCGAGTGT & AAGCCCTTACAGCCTTCACATG & 89 \\
PPAR $/ \delta$ & GGAACAGCCACAGGAGGA & AGGGAGGAAGGGGAGGAA & 155 \\
PPAR $\gamma$ & AGACCACTCGCATTCCTTTG & TCGCACTTTGGTATTCTTGG & 154 \\
GLUT4 & GGCATGCGTTTCCAGTATGT & GCCCCTCAGTCATTCTCATC & 233 \\
PDK4 & TCCTTCACACCTTCACCACA & AAAGAGGCGGTCAGTAATCC & 190 \\
mCPT1 & GGGCAGACGCGCCCATCATT & GCTCGGGAATGTCCCACGGC & 150 \\
UCP2 & CCGGCTTCTGCACCACCGTC & GGGGTCCCTCCTTCCGGAGC & 129 \\
UCP3 & GGAGGAGAGAGGAAATACAGAGG & CCAAAGGCAGAGACAAAGTGA & 218 \\
InsR & CTCCTGGGATTCATGCTGTT & GTCCGGCGTTCATCAGAG & 242 \\
OB-Rb & CCTGTGCACATTCCCAGCCCA & ACTGGAACGGAACCTTGAGGCTTT & 230 \\
SOCS3 & ACTGAGCCGACCTCTCTCCT & CCCCTCTGACCCTTTCTTTG & 172 \\
IL6 & GGTGACAACCACGGCCTTCCC & AAGCCTCCGACTTGTGAAGTGGT & 105 \\
IL15 & TGTCTTCATTTTGGGCTGTG & TGCAACTGGGATGAAAGTCA & 155 \\
\hline
\end{tabular}

Real-time quantitative PCR analysis

Real-time polymerase chain reaction (PCR) was used to measure mRNA expression levels of PGC1 $\alpha$, PGC1 $\beta$, UCP2, UCP3, PPAR $\alpha$, PPAR $\beta / \delta$, PPAR $\gamma$, PDK4, OB-Rb, InsR, GLUT4, IL6, IL15, muscle isoform mCPT1, and SOCS3 in C2C12 cells. $0.25 \mu \mathrm{g}$ of total RNA (in a final volume of $12.5 \mu \mathrm{l}$ ) was denatured at $65^{\circ} \mathrm{C}$ for 10 min and then reverse transcribed to cDNA using murine leukemia virus reverse transcriptase (Applied Biosystems, Madrid, Spain) at $20^{\circ} \mathrm{C}$ for $15 \mathrm{~min}, 42^{\circ} \mathrm{C}$ for $30 \mathrm{~min}$, with a final step of $5 \mathrm{~min}$ at $95^{\circ} \mathrm{C}$ in an Applied Biosystems 2720 Thermal Cycler. Each PCR done afterwards was performed with diluted (1/5) cDNA template, forward and reverse primers $(1 \mu \mathrm{M}$ each) and Power SYBER GreenPCRMaster Mix (Applied Biosystems).

Real-time PCR was performed using the Applied Biosystems StepOnePlusTM Real-Time PCR Systems with the following profile: $10 \mathrm{~min}$ at $95^{\circ} \mathrm{C}$, followed by a total of 40 temperature cycles $\left(15 \mathrm{~s}\right.$ at $95^{\circ} \mathrm{C}$ and 1 $\min$ at $60^{\circ} \mathrm{C}$ ). To verify the purity of the products, a melting curve was produced after each run according to the manufacturer's instructions. The threshold $(\mathrm{Ct})$ values were determined by the instrument's software (StepOne Software version 2.1, Applied Biosystems). 18S ribosomal RNA was used as reference gene. All primers were obtained from Sigma Genosys (Sigma Aldrich). Primers for the different genes are described in Table 1.

\section{Western blotting}

The amount of PGC1 $\alpha$ in C2C12 cells (treated with leptin 50ng/ml for 3, 12 and 24h) was determined by Western blot analysis. $40 \mu \mathrm{g}$ of total protein was solubilized and boiled for $3 \mathrm{~min}$ in Laemmli sample buffer containing 5\% 2-mercaptoethanol. Then, total protein was fractionated by SDS-PAGE (10\% polyacrylamide) and electrotransferred onto a nitrocellulose membrane (Bio-Rad, Madrid, Spain). After blocking in Odyssey blocking buffer (LI-COR, Lincoln, Nebraska, USA), the membrane was incubated with the primary rabbit polyclonal anti-PGC1 $\alpha$ H-300 antibody (Santa Cruz Biotechnology, Inc., Santa Cruz, CA), diluted 1:1000 for 1h at room temperature (RT), and then washed $3 \times 5^{\prime}$ with TBS-Tween; afterwards, the membrane was incubated with the primary mouse monoclonal anti- $\beta$-actin antibody (Cell Signaling Technology, Inc., Danvers, MA, USA) diluted 1:1000 for 30' at RT, washed again 3 times with TBS-Tween (15' and 2x5') and then incubated with the corresponding infrared-dyed secondary IgG antibodies (LI-COR Biosciences) diluted 1:10.000. The membrane was scanned by using the Odyssey Infrared Imaging System (LI-COR Biosciences).

\section{Statistical analysis}

The data represent the mean \pm SEM of three separate experiments performed in duplicate. The results are given as a percentage increase of each treated time point with respect to their respective time controls. Differences between treated groups and their corresponding time-controls were assessed by Student's t test. 


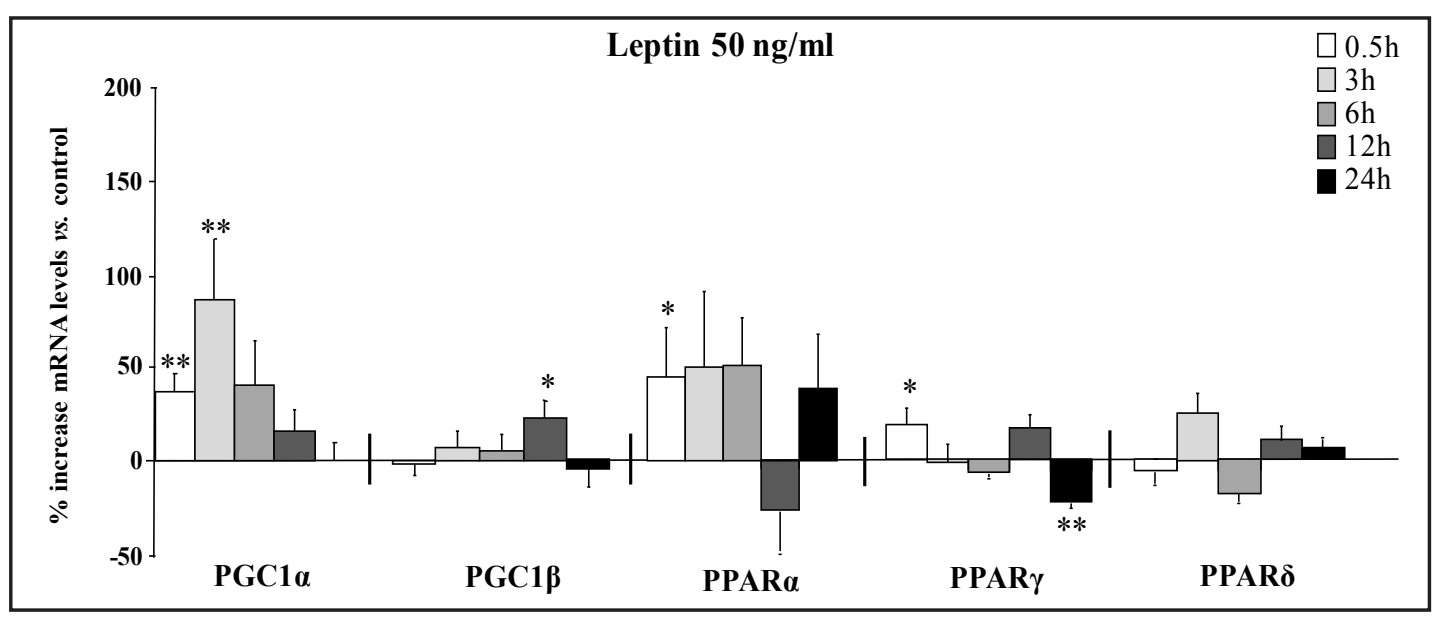

Fig. 1. Time-course mRNA expression of transcriptional activators and co-activators in response to leptin (50ng/ml) in C2C12 muscle cells. mRNA expression is referred to the matching time-control for each time point studied and given as a percentage increase with respect to the corresponding control. Data represent the mean \pm SEM of three separate experiments performed in duplicate. Student's $t$ test: ${ }^{* *}$ significant differences at $\mathrm{p}<0.05$, *significant differences at $\mathrm{p}<0.1$.

Fig. 2. Time-course protein expression of PGC1 $\alpha$ in response to leptin in C2C12 muscle cells: A) representative bands in Western blot, B) leptin 50ng/ ml. Data are processed as explained in Fig. 1. Student's t test: ${ }^{* *}$ significant differences at $\mathrm{p}<0.05$.

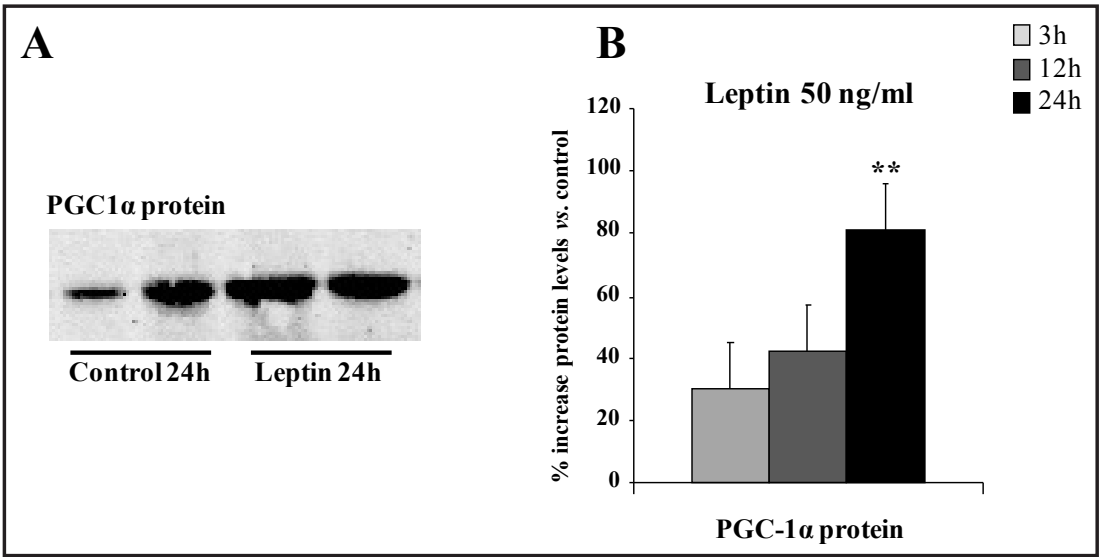

The analyses were performed with SPSS for Windows (SPSS, Chicago, IL, USA). Threshold of significance was defined at $\left.\mathrm{p}<0.05{ }^{* *}\right)$, or $\mathrm{p}<0.1\left(^{*}\right)$.

\section{Results}

The most evident and significant differences were observed upon leptin treatment at two different concentrations: $10 \mathrm{ng} / \mathrm{ml}$ and $50 \mathrm{ng} / \mathrm{ml}$, especially $50 \mathrm{ng} / \mathrm{ml}$, and the significant results are shown in Figures 1-5.

Effects of leptin on the expression of transcriptional activators and co-activators

As shown in Figure 1, in differentiated C2C12 myotubes, treatment with leptin 50ng/ ml caused a significant rise in the mRNA levels of PGC1 $\alpha$ very early on, at 30' and 3h (almost doubling the control levels) of treatment, afterwards returning to basal levels. There was a less significant increase in mRNA levels (significant at $\mathrm{p}<0.1$ ) of PGC1 $\beta$ (at $12 \mathrm{~h}$ ) and PPAR $\alpha$ and PPAR $\gamma$ (at $30^{\prime}$ ), with a significant decrease of the latter at $24 \mathrm{~h}$ and without significant changes for PPAR $\delta$ mRNA expression. 


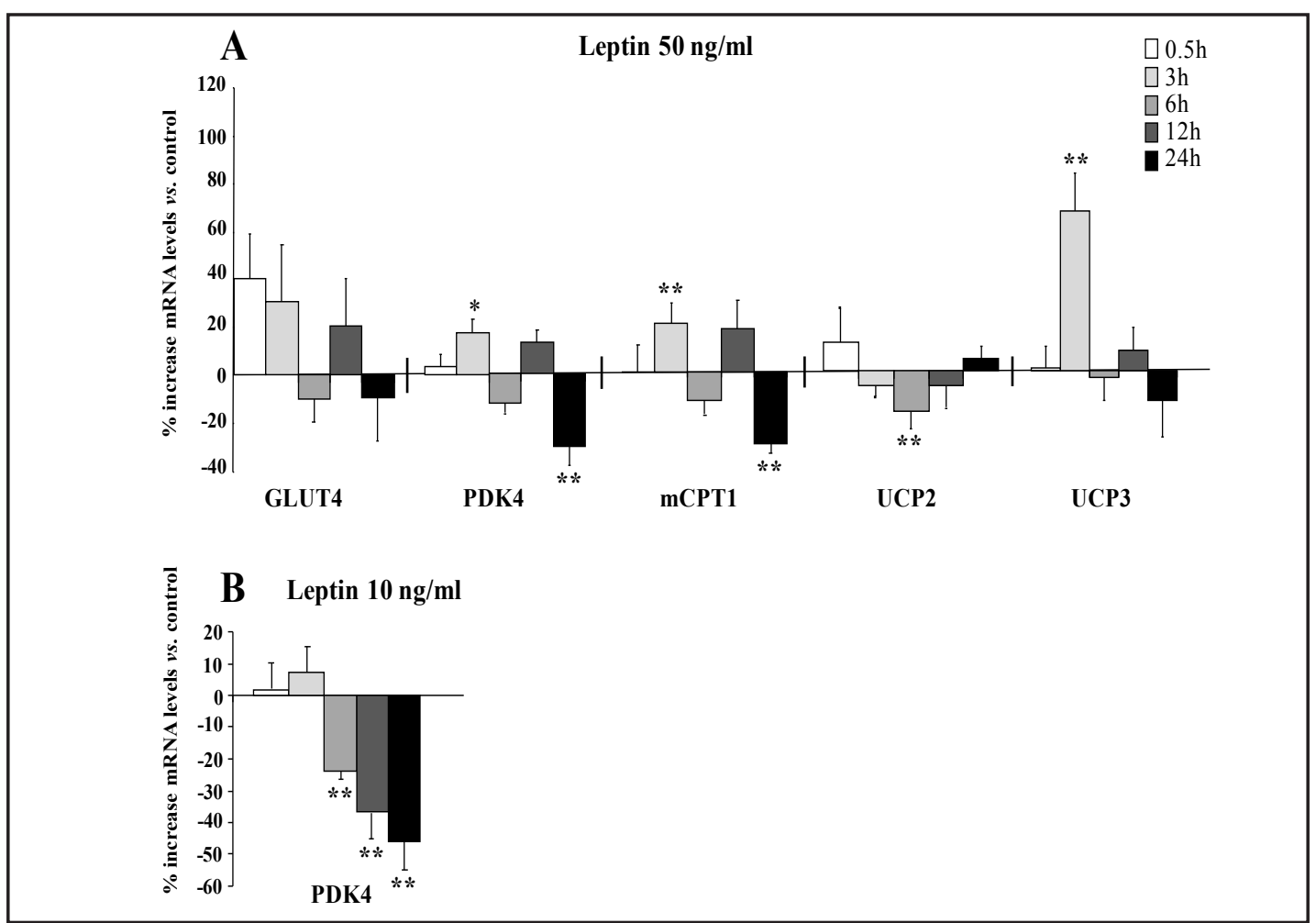

Fig. 3. Time-course mRNA expression of key molecules in fuel selection and use in response to leptin in C2C12 muscle cells: A) leptin 50ng/ml, B) leptin 10ng/ml. Data are processed as explained in Fig. 1. Student's t test: ${ }^{* *}$ significant differences at $\mathrm{p}<0.05$, *significant differences at $\mathrm{p}<0.1$.

Moreover, the early increase in PGC1 $\alpha$ mRNA expression was later accompanied by a gradual increase in PGC1 $\alpha$ protein levels, which were significantly elevated (almost double) after $24 \mathrm{~h}$ of treatment with leptin $50 \mathrm{ng} / \mathrm{ml}$ (Fig. 2).

Effects of leptin on the expression of key molecules in fuel selection and use

The greatest effect of $50 \mathrm{ng} / \mathrm{ml}$ leptin treatment was observed for UCP3 mRNA levels, which were elevated relatively soon after the beginning of the treatment (3h), accompanied with a significant elevation of mCPT1 mRNA levels at the same time point (see Fig. 3A) and a tendency to induce PDK4 mRNA levels (significant at the $\mathrm{p}<0.1$ level). On the other hand, there was a descent of the same mCPT1 mRNA after 24h of treatment, and of UCP2 mRNA levels after $6 \mathrm{~h}$ of treatment. Moreover, the main effect of leptin on PDK4 expression was to induce a significant decrease in its mRNA levels after $24 \mathrm{~h}$ of treatment at the concentration of $50 \mathrm{ng} / \mathrm{ml}$ (Fig. 3A), and curiously the effect was more marked with a lower concentration of leptin $(10 \mathrm{ng} / \mathrm{ml})$ with which there was a significant and progressive decrease of PDK4 expression from $6 \mathrm{~h}$ of treatment onwards (Fig. 3B). No effects were observed for GLUT4 mRNA expression.

Effects of leptin on the expression of insulin and leptin receptors and the suppressor of cytokine signaling SOCS3

Leptin treatment caused a significant effect of induction in the expression of its receptor (OB-Rb) at $3 \mathrm{~h}$ of treatment, both similarly seen with the treatments of $10 \mathrm{ng} / \mathrm{ml}$ $(266.5 \pm 153.3 \%$ increase, $\mathrm{p}<0.05)$ and $50 \mathrm{ng} / \mathrm{ml}$ (Fig. 4 , significant at $\mathrm{p}<0.1$ ), without effects on SOCS3 expression. On the other hand, leptin treatment caused a dual contrary effect on InsR mRNA expression, by inducing it after $3 \mathrm{~h}$ of treatment when given at a concentration of $50 \mathrm{ng} / \mathrm{ml}$ (Fig. 4) and by decreasing its mRNA levels after $12 \mathrm{~h}$ when given at a concentration of $10 \mathrm{ng} / \mathrm{ml}(-34.9 \pm 4.9 \%$ decrease, $\mathrm{p}<0.05)$. 


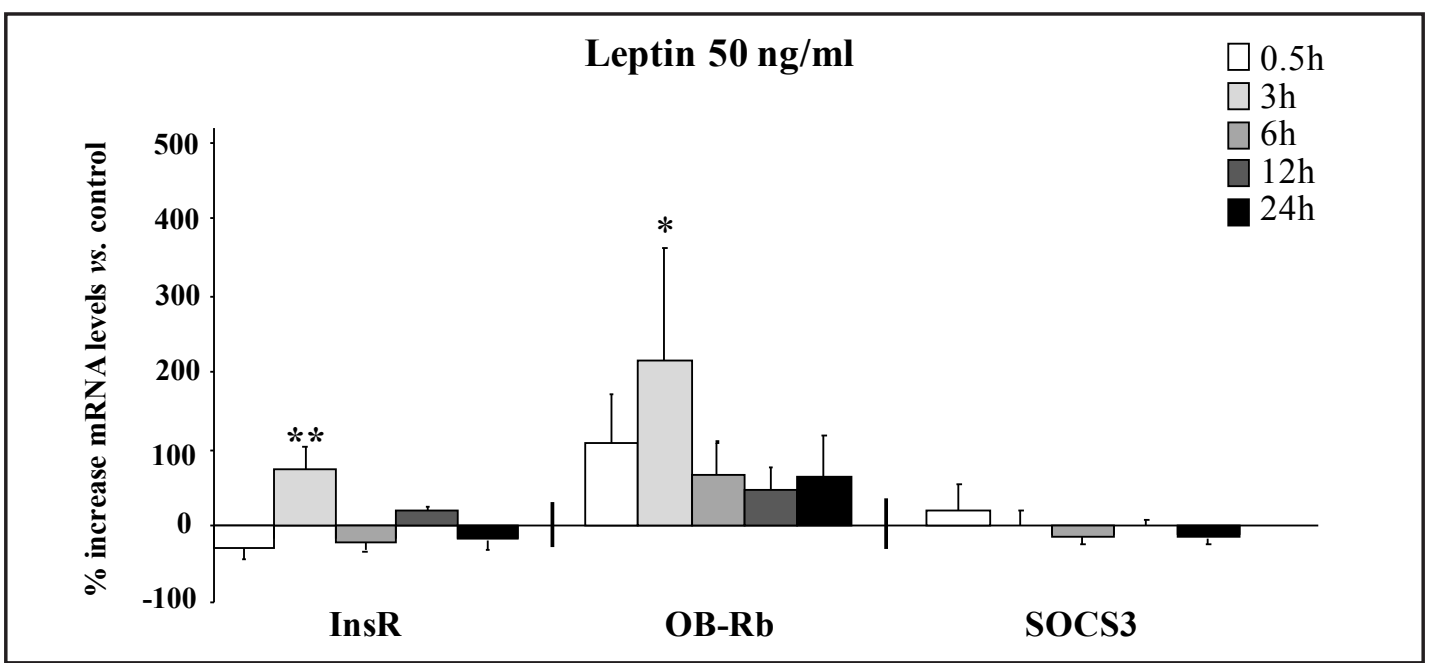

Fig. 4. Time-course mRNA expression of insulin and leptin receptors, and SOCS3, in response to leptin (50ng/ $\mathrm{ml}$ ) in C2C12 muscle cells. Data are processed as explained in Fig. 1. Student's t test: ${ }^{* *}$ significant differences at $\mathrm{p}<0.05$, *significant differences at $\mathrm{p}<0.1$.

Fig. 5. Time-course mRNA expression of myokines in response to leptin (50ng/ml) in C2C12 muscle cells. Data are processed as explained in Fig. 1. Student's t test: ** significant differences at $\mathrm{p}<0.05, *$ significant differences at $\mathrm{p}<0.1$.

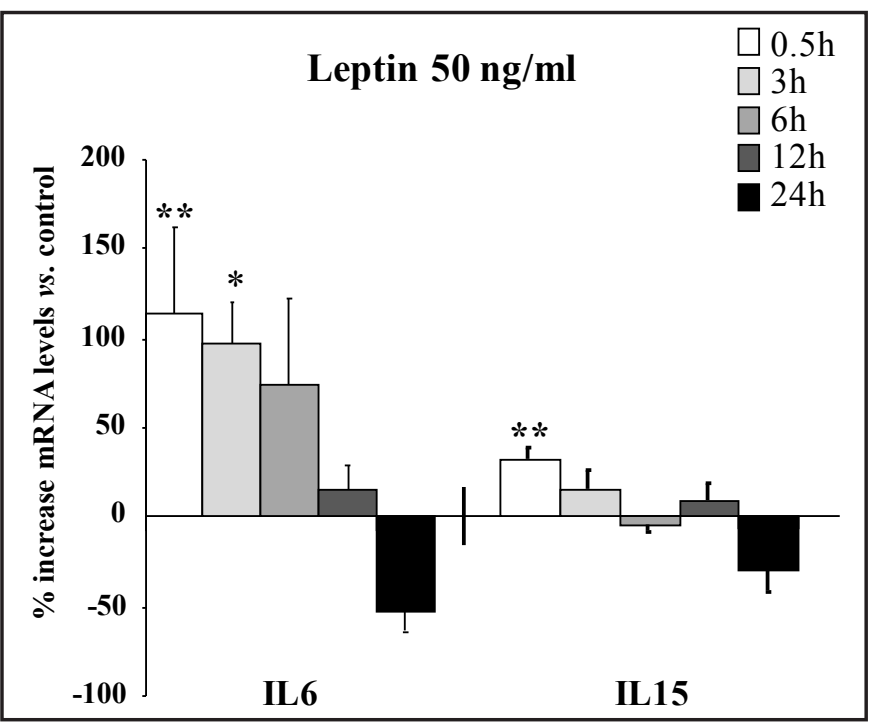

Effects of leptin on the expression of the myokines IL6 and IL15

Although leptin showed a little yet significant effect on IL15 mRNA expression early on (30') by inducing it when given at a concentration of $50 \mathrm{ng} / \mathrm{ml}$ (Fig. 5), the greatest effect was observed for IL6 expression, which was also significantly induced by $50 \mathrm{ng} / \mathrm{ml}$ of leptin treatment very early on (at $30^{\prime}-\mathrm{p}<0.05-$ and maintained at $3 \mathrm{~h}-\mathrm{p}<0.1$ ) but decreased afterwards (Fig. 5), and even with a significant effect on IL6 mRNA expression induction with the treatment of leptin $10 \mathrm{ng} / \mathrm{ml}$ after $3 \mathrm{~h}(89.5 \pm 46 \%$ increase, $\mathrm{p}<0.05)$ and $6 \mathrm{~h}(96.6 \pm 33.1 \%$ increase, $\mathrm{p}<0.1$ ).

\section{Discussion}

The results of our study show that leptin administration in differentiated myotubes has a rapid effect on the expression of different strategic molecules related to the control of energy metabolism, particularly PGC1 $\alpha$, mCPT1, PDK4, UCP3 and IL6. The tested concentrations of leptin are within physiological range in the circulation/plasma; e.g. concentrations in 
serum of NMRI non-obese control mice (which are approx. between $20-50 \mathrm{ng} / \mathrm{ml}$ in $4-6$ month-old animals) [24]. The induction of the expression at mRNA level of the master transcriptional co-activator PGC1 $\alpha$ is transient but rapid and evident as early as $30^{\prime}$ after leptin administration, and is even more elevated after $3 \mathrm{~h}$ (Fig. 1), and thereafter reflected in the increase of PGC1 $\alpha$ protein levels (gradually increasing and becoming significantly greater after 24h) (Fig. 2). Regarding this, two important questions must be outlined: 1) due to the key functions of PGC1 $\alpha$, this effect may be directly related to other transcriptional changes observed in this work and the rapid response may suggest that PGC1 $\alpha$ may be a key molecule orchestrating ulterior effects of leptin in the cells, and 2) how can the expression of PGC1 $\alpha$ when leptin acts on muscle cells be increased. With respect to the first question, this is not the first time we have observed a rapid transient increase of PGC1 $\alpha$ expression which may be related with posterior transcriptional changes facing a metabolic challenge; we have reported that sequential fasting in rat muscle in vivo and FFA (oleic/linoleic) or adrenaline treatment of C2C12 cells cause a peak of increased PGC1 $\alpha$ mRNA levels after $4 \mathrm{~h}$ (fasting) or $3 \mathrm{~h}$ (FFA or adrenaline), thereafter returning to basal levels in all cases [7, 8]. To address the second question, it is important to note that in muscle cells leptin is able to activate the catalytic $\alpha 2$ subunit of AMPK promoting its kinase activity on downstream molecules [5]. In the literature, the activation of AMPK has been reported to promote the activation of the deacetylase SIRT1 (Sirtuin 1) which is believed, according to one of the proposed theories, to activate PGC1 $\alpha$ protein by deacetylation [25]; it has been reported that direct phosphorylation of PGC1 $\alpha$ by AMPK also promotes the activity of the transcriptional coactivator [26]; moreover, activated AMPK has been suggested to increase PGC1 $\alpha$ expression in muscle [26-28] and such an effect would probably be achieved through an auto-regulatory loop of PGC1 $\alpha$ on its own promoter $[29,30]$. Thus, following this reasoning, a good explanation for the induction of PGC1 $\alpha$ expression observed here would be the activation of AMPK by leptin treatment. Nevertheless, the answer may not be that simple. Although Jäger et al. [26] observed an increase in PGC1 $\alpha$ expression with AICAR (precursor of an AMP mimetic able to directly activate AMPK) in primary myotubes after $16 \mathrm{~h}$ of treatment, and other works have shown that activation of AMPK with exercise or AICAR increases the expression of PGC1 $\alpha$ (although in in vivo models) $[27,28]$, we have previously described that the treatment of C2C12 differentiated myotubes (following again a similar sequential model to the one used here) with AICAR alone is not able to induce PGC1 $\alpha$ expression at all, but rather has to be accompanied by other signals (such as adrenaline or free fatty acids) acting at the same time [8]. Therefore, the clear, direct (on muscle cells), early effect of leptin on PGC1 $\alpha$ expression reported here is, to our knowledge, something new and the possible mechanism leading to it would be somewhat complex, involving other effects of leptin on muscle cells beyond its capacity to stimulate AMPK activity. More research to decipher the possible pathways involved would be of interest, such as the study of the implication of the JAK/STAT, Akt and ERK signaling pathways, known to be activated by leptin in muscle cells $[3,6]$. With respect to the other PGC1 family member studied, PGC1 $\beta$, we have only observed a slight tendency to induce its expression after $12 \mathrm{~h}$ of leptin treatment, and therefore a possible impact on oxidative capacity mediated by this co-activator may be possible, although from the results shown here it seems that the leptin effect may be more significant through PGC1 $\alpha$ induction.

At transcriptional level, the present results show that for PPARs the main effects are the slight tendency to early induce PPAR $\alpha$ and PPAR $\gamma$ mRNA levels (Fig. 1), which may have an impact on the metabolic capacity of the muscle cells (both are involved in the stimulation of fatty acid oxidation in skeletal muscle [13-15]). We have not addressed the direct activation of the transcriptional activity of these nuclear receptors, but it is feasible to think that their slightly higher expression levels, together with the greater expression of PGC1 $\alpha$, would prepare the cells treated with leptin to have an enhanced oxidative capacity. In fact other studies have reported that leptin treatment in muscle cells activate the DNA binding activity of the three PPARs [31], and the expression of PPAR $\alpha$ by inducing the nuclear translocation of the $\alpha 2$ subunit of AMPK [32], in line with this same idea of the important impact of leptin on gene expression and oxidative capacity in muscle cells.

\section{KARGER}


The results obtained for the effect of leptin in mCPT1, PDK4 and UCP3 (Fig. 3) expression also support the idea that leptin treatment in muscle cells would have a major impact inducing oxidative capacity and managing the fuel substrate to be mainly used. In this sense, although long treatment $(24 \mathrm{~h})$ with leptin results in a down-regulation of mCPT1, at early stages (after $3 \mathrm{~h}$ of treatment in this case), it causes an up-regulation, which may be translated into a higher capacity to derive fatty acids for their oxidation in the mitochondria [22]. This result is accompanied by the marked induction of UCP3 expression relatively early on (at 3h), which is suggested to be involved in the export of fatty acid anions during lipid oversupply protecting mitochondria from lipotoxicity $[19,20]$. Thus, the expressioninducing early effect of leptin in mCPT1 and UCP3 (which is more specific to muscle cells than UCP2 [33]) would be along the same lines of preparing the muscle cells for greater oxidative metabolism of lipids, whereas UCP2 expression would even be slightly reduced by leptin (at 6h), suggesting a significantly different regulation between both UCPs by leptin in muscle cells. Contrary to our results, the induction of UCP2 expression (mRNA levels) with leptin in a similar serum-free model in C2C12 myotubes has been previously described, but significantly higher concentrations of leptin were used [34]. On the other hand, PDK4 expression (Fig. 3A-B) is progressively and markedly down regulated by leptin at $10 \mathrm{ng} / \mathrm{ml}$ and less markedly with the greater $50 \mathrm{ng} / \mathrm{ml}$ leptin concentration (only evident after $24 \mathrm{~h}$ treatment) but with a tendency to be up-regulated at $3 \mathrm{~h}(\mathrm{p}<0.1)$. Since PDK4 phosphorylates and inhibits the PDH complex and is therefore involved in fuel selection (inhibiting the whole oxidation of glucose) [35], these results together with the induction of PGC1 $\alpha$, PPARs, mCPT1 and UCP3 suggest that leptin treatment would prepare the muscle cell to increase both lipid and glucose oxidation. The time-course design of this study allows us to go into further detail: in the short-term (3h) there is a significant induction of mCPT1 expression and a tendency to up-regulate PDK4 mRNA, which would be in line with preparing the cell for a preference to burn lipids rather than to completely oxidize glucose (preserving the $3 \mathrm{C}$ compounds derived from glycolysis), while in the long-term (24h) there is a significant downregulation of both PDK4 mRNA and mCPT1, which may allow the cell to derive the selection of fuel to increased oxidation of glucose and less marked (compared to the first hours of induction) oxidation of lipids. However, this does not mean that whole lipid oxidation may be decreased, since Akasaka et al. [34] showed in C2C12 myotubes that palmitate oxidation is increased with respect to control cells after $24 \mathrm{~h}$ of leptin treatment (although with a high concentration of leptin). This idea opens the possibility of a putative dual role of leptin in fuel selection in muscle cells, which would also deserve additional studies addressing not only expression at mRNA level. Moreover, with respect to PDK4 mRNA down-regulation, we have also observed in previous experiments (unpublished data) that treatment of C2C12 cells with AICAR also causes a marked reduction in PDK4 mRNA levels, and other authors [36] have also described a decrease of PDK4 expression with AICAR in primary human myotubes. To our knowledge, this is the first time that the inhibitory effect of leptin on PDK4 in muscle cells has been described and, in addition, given the effect of AICAR on it, we can hypothesize that the effect of leptin on PDK4 levels may be mediated, at least in part, by AMPK activation. Likewise, in our previous work analyzing the effect of sequential fasting and refeeding in rat soleus (highly oxidative) and gastrocnemius (mixed oxidative/glycolytic muscle) [7] we reported a similar (especially in gastrocnemius), but inverse (by increasing its expression) time-dependent pattern of response of PDK4 expression to fasting (when leptin falls) with a partial reversion of short refeeding, which may be associated with changes in circulating leptin [9], which follows a similar time-pattern of changes; i.e. there is a sequential increase of gastrocnemius PDK4 expression with 4, 8 and 24h fasting and a sequential decrease of circulating leptin levels (same hours) with a partial recovery of both with $3 \mathrm{~h}$ refeeding [7, 9]. Altogether, these results suggest leptin may be a crucial hormone in regulating PDK4 expression (and thus fuel partitioning) in muscle cells.

In our work, we also wanted to address the effect of leptin on muscle cells in promoting or impairing their sensitivity to leptin and insulin (Fig. 4). Although there is an induction of InsR expression in the short term (3h) with leptin $50 \mathrm{ng} / \mathrm{ml}$, an opposite effect after $12 \mathrm{~h}$ 
of treatment with leptin $10 \mathrm{ng} / \mathrm{ml}$ is shown (see results section). Only with the parameters studied here, it is difficult to explain the dose-time-dependent effect of leptin on InsR expression, but it may have a possible impact on insulin receptor expression to modulate/ adjust insulin sensitivity. Contrarily, in terms of the expression of the long form of the leptin receptor (OB-Rb) it seems that the effect of the hormone would be to induce its expression (more markedly with the treatment of $10 \mathrm{ng} / \mathrm{ml}$, see results section), without effects on SOCS3 expression, thus suggesting a possible slight effect of leptin inducing a greater sensitivity to its own effects, at least with not really prolonged treatments (the longest treatment here lasts 24h). A similar effect on OB-Rb expression was observed by Maroni et al. [37] with short leptin treatment (30'), involving the signaling proteins Sam68 and ERKs. Although we do not observe significant changes of leptin treatment on SOCS3 expression, other authors [38] have described the induction of SOCS3 expression by leptin in vitro; nevertheless, this discrepancy can be due to various factors such as a different cell line (L6 myocites), different medium conditions and especially significantly higher concentration of leptin. It must be outlined that in our experimental model we aimed to characterize the effect of relatively low/physiological concentrations of leptin.

With respect to the influence on key myokines, we addressed the study of leptin effect on IL6 an IL15 expression. Both IL6 and IL15 mRNA were up-regulated by leptin (50ng/ ml) treatment after 30', but with a more marked effect on IL6 mRNA (Fig. 5), which was also up-regulated with the concentration of $10 \mathrm{ng} / \mathrm{ml}$ (see results section). We have not found previous similar studies of the effect of leptin on IL6 or IL15 expression in muscle cells and it is interesting to note that if leptin has the ability to regulate their expression it may have important non-described effects on muscle cells. Both ILs have been related to the positive effects of exercise, and seem to regulate muscle growth or metabolism [12]. IL6 has been especially related to the crosstalk with adipose tissue and the promotion of insulin sensitivity and to the crosstalk with leptin signaling, and is also able to activate AMPK [12]. Therefore, since leptin shows a rapid impact on IL expression, it may have an important influence on muscle cell physiology by inducing ILs, especially IL6 expression, and by further activating AMPK.

In summary, we show here that leptin treatment has profound effects on muscle cell gene expression, with a rapid response of key genes involved in nutrient partition and oxidation and in other signaling pathways. Moreover, we have previously shown in in vivo and in vitro models $[7,8]$ that some of the key genes that show here the most marked and rapid response to leptin, such as the ones encoding PGC1 $\alpha$, UCP3, PDK4 and IL6, also rapid and markedly respond to other physiological conditions such as fasting, refeeding and free fatty acid oversupply, thus underpinning the possible crucial importance of these genes in muscle cell physiology, which may be therapeutic targets for conditions of muscle metabolism malfunctioning such as obesity, diabetes and sedentary lifestyle.

\section{Acknowledgements}

This work was supported by the Spanish Government (project BIOBESMARKERS, AGL2009-11277) and the European Commission (project BIOCLAIMS, FP7-244995). Mr. Nozhenko was granted by the Spanish Ministry of Foreign Affairs and Cooperation. The Laboratory of Molecular Biology, Nutrition and Biotechnology (Nutrigenomics) is a member of the European Research Network of Excellence NuGO (The European Nutrigenomics Organization, www.nugo.org). The CIBER Fisiopatología de la obesidad y nutrición is an initiative of the ISCIII.

\section{References}

1 Dyck DJ: Leptin sensitivity in skeletal muscle is modulated by diet and exercise. Exerc Sport Sci Rev 2005;33:189-194. 
Nozhenko/Rodríguez/Palou: Leptin and Metabolic Pattern in Muscle Cells

2 Sarvas JL, Khaper N, Lees SJ: The il-6 paradox: Context dependent interplay of socs3 and ampk. J Diabetes Metab 2013;Suppl 13

3 Frühbeck G: Intracellular signalling pathways activated by leptin. Biochem J 2006;393:7-20.

4 Anubhuti, Arora S: Leptin and its metabolic interactions: An update. Diabetes Obes Metab 2008;10:973993.

-5 Minokoshi Y, Kim YB, Peroni OD, Fryer LG, Müller C, Carling D, Kahn BB: Leptin stimulates fatty-acid oxidation by activating amp-activated protein kinase. Nature 2002;415:339-343.

6 Moon HS, Chamberland JP, Mantzoros CS: Amylin and leptin activate overlapping signalling pathways in an additive manner in mouse gt1-7 hypothalamic, $\mathrm{c}_{2} \mathrm{c}_{12}$ muscle and aml12 liver cell lines. Diabetologia 2012;55:215-225.

7 Rodríguez AM, Sánchez J, Tobaruela A, Priego T, Picó C, Palou A: Time-course effects of increased fatty acid supply on the expression of genes involved in lipid/glucose metabolism in muscle cells. Cell Physiol Biochem 2010;25:337-346.

-8 Sánchez J, Nozhenko Y, Palou A, Rodríguez AM: Free fatty acid effects on myokine production in combination with exercise mimetics. Mol Nutr Food Res 2013;57:1456-1467.

-9 Palou M, Sánchez J, Rodríguez AM, Priego T, Picó C, Palou A: Induction of npy/agrp orexigenic peptide expression in rat hypothalamus is an early event in fasting: Relationship with circulating leptin, insulin and glucose. Cell Physiol Biochem 2009;23:115-124.

10 Ahima RS, Prabakaran D, Mantzoros C, Qu D, Lowell B, Maratos-Flier E, Flier JS: Role of leptin in the neuroendocrine response to fasting. Nature 1996;382:250-252.

11 Argilés JM, López-Soriano FJ, Busquets S: Therapeutic potential of interleukin-15: A myokine involved in muscle wasting and adiposity. Drug Discov Today 2009;14:208-213.

12 Pedersen BK: Exercise-induced myokines and their role in chronic diseases. Brain Behav Immun 2011;25:811-816.

13 Evans RM, Barish GD, Wang YX: Ppars and the complex journey to obesity. Nat Med 2004;10:355-361.

14 Sugden MC, Zariwala MG, Holness MJ: Ppars and the orchestration of metabolic fuel selection. Pharmacol Res 2009;60:141-150.

15 Grygiel-Górniak B: Peroxisome proliferator-activated receptors and their ligands: Nutritional and clinical implications--a review. Nutr J 2014;13:17.

16 Chan MC, Arany Z: The many roles of pgc-1 $\alpha$ in muscle--recent developments. Metabolism 2014;63:441451.

17 Scarpulla RC: Metabolic control of mitochondrial biogenesis through the pgc-1 family regulatory network. Biochim Biophys Acta 2011;1813:1269-1278.

18 Villarroya F, Iglesias R, Giralt M: Ppars in the control of uncoupling proteins gene expression. PPAR Res 2007;2007:74364.

19 Mailloux RJ, Harper ME: Uncoupling proteins and the control of mitochondrial reactive oxygen species production. Free Radic Biol Med 2011;51:1106-1115.

20 Nabben M, Hoeks J: Mitochondrial uncoupling protein 3 and its role in cardiac- and skeletal muscle metabolism. Physiol Behav 2008;94:259-269.

-21 Govers R: Molecular mechanisms of glut4 regulation in adipocytes. Diabetes Metab doi: 10.1016/j. diabet.2014.01.005

22 Jeukendrup AE: Regulation of fat metabolism in skeletal muscle. Ann N Y Acad Sci 2002;967:217-235.

23 Pedersen BK, Febbraio MA: Muscle as an endocrine organ: Focus on muscle-derived interleukin-6. Physiol Rev 2008;88:1379-1406.

-24 Felipe F, Mercader J, Ribot J, Palou A, Bonet ML: Effects of retinoic acid administration and dietary vitamin a supplementation on leptin expression in mice: Lack of correlation with changes of adipose tissue mass and food intake. Biochim Biophys Acta 2005;1740:258-265.

25 Cantó C, Gerhart-Hines Z, Feige JN, Lagouge M, Noriega L, Milne JC, Elliott PJ, Puigserver P, Auwerx J: Ampk regulates energy expenditure by modulating nad+ metabolism and sirt1 activity. Nature 2009;458:10561060.

-26 Jäger S, Handschin C, St-Pierre J, Spiegelman BM: Amp-activated protein kinase (ampk) action in skeletal muscle via direct phosphorylation of pgc-1alpha. Proc Natl Acad Sci U S A 2007;104:12017-12022.

27 Baar K, Wende AR, Jones TE, Marison M, Nolte LA, Chen M, Kelly DP, Holloszy JO: Adaptations of skeletal muscle to exercise: Rapid increase in the transcriptional coactivator pgc-1. FASEB J 2002;16:1879-1886. 
Nozhenko/Rodríguez/Palou: Leptin and Metabolic Pattern in Muscle Cells

28 Suwa M, Nakano H, Kumagai S: Effects of chronic aicar treatment on fiber composition, enzyme activity, ucp3, and pgc-1 in rat muscles. J Appl Physiol 2003;95:960-968.

29 Cantó C, Auwerx J: Amp-activated protein kinase and its downstream transcriptional pathways. Cell Mol Life Sci 2010;67:3407-3423.

-30 Handschin C, Rhee J, Lin J, Tarr PT, Spiegelman BM: An autoregulatory loop controls peroxisome proliferator-activated receptor gamma coactivator 1alpha expression in muscle. Proc Natl Acad Sci U S A 2003;100:7111-7116.

31 Bendinelli P, Piccoletti R, Maroni P: Leptin rapidly activates ppars in c2c12 muscle cells. Biochem Biophys Res Commun 2005;332:719-725.

32 Suzuki A, Okamoto S, Lee S, Saito K, Shiuchi T, Minokoshi Y: Leptin stimulates fatty acid oxidation and peroxisome proliferator-activated receptor alpha gene expression in mouse c2c12 myoblasts by changing the subcellular localization of the alpha2 form of amp-activated protein kinase. Mol Cell Biol 2007;27:4317-4327.

-33 Azzu V, Brand MD: The on-off switches of the mitochondrial uncoupling proteins. Trends Biochem Sci 2010;35:298-307.

-34 Akasaka Y, Tsunoda M, Ide T, Murakami K: Chronic leptin treatment stimulates lipid oxidation in immortalized and primary mouse skeletal muscle cells. Biochim Biophys Acta 2009;1791:103-109.

-35 Sugden MC: Pdk4: A factor in fatness? Obes Res 2003;11:167-169.

-36 McAinch AJ, Cameron-Smith D: Adiponectin decreases pyruvate dehydrogenase kinase 4 gene expression in obese- and diabetic-derived myotubes. Diabetes Obes Metab 2009;11:721-728.

37 Maroni P, Citterio L, Piccoletti R, Bendinelli P: Sam68 and erks regulate leptin-induced expression of ob-rb mrna in c2c12 myotubes. Mol Cell Endocrinol 2009;309:26-31.

-38 Eguchi M, Gillis LC, Liu Y, Lyakhovsky N, Du M, McDermott JC, Sweeney G: Regulation of socs-3 expression by leptin and its co-localization with insulin receptor in rat skeletal muscle cells. Mol Cell Endocrinol 2007;267:38-45. 